\title{
DETERMINATION OF EFFECTIVE HEAT TRANSPORT COEFFICIENTS FOR WALL-COOLED PACKED BEDS
}

\author{
J.G.H. BORKINK and K.R. WESTERTERP * \\ Chemical Reaction Engineering Laboratories \\ Department of Chemical Engineering \\ Twente University of Technology \\ PO-Box 217, 7500 AE Enschede, The Netherlands \\ - Author to whom correspondence should be addressed.
}

Key words: heat transport coefficient, packed bed, boundary condition, crosscorrelation, length dependence, velocity profile.

\begin{abstract}
THE INFLUENCE IS STUDIED OF SEVERAL ASSUMPTIONS. OFTEN MADE IN LITERATURE. ON THE VALUES FOR THE EFFECTIVE RADIAL HEAT CONDUCTIVITY. WALL HEAT TRANSFER COEFFICIENT AND OVERALL HEAT TRANSFER COEFFICIENT. AS OBTAINED FROM EXPERIMENTS IN WALL-COOLED PACKED BEDS WITHOUT A CHEMICAL REACTION. ESPECIALLY THE CHOICE OF THE INLET BOUNDARY CONDITION CAN HAVE A LARGE IMPACT ON THE VALUES OBTAINED. THE INFLUENCE OF THE PRESENCE OF A RADIAL VELOCITY PROFILE AND ALSO THE CROSS-CORAELATION OF THE PARAMETERS OBTAINED IS STUDIED.
\end{abstract}

\section{INTRODUCTION}

For performing highly exothermic, catalytic reactions in industry often a cooled tubular reactor is used. A major problem with such a reactor is runaway to very high temperatures. It is important to prevent this and to study the behaviour of such a reactor a-priori by computer simulation. For this purpose a good mathematical reactor model is needed, capable of predicting the temperature and concentration profiles in the reactor, given a certain reactor design and operating conditions. Here the description of heat transport in wall-cooled packed beds at a low tube-to-particle diameter ratio, using the pseudo-homogeneous one-and two-dimensional continuum models, is discussed.

\section{MODEL EQUATIONS}

The system studied is a hot gas, cooled down in a wall-cooled packed tube with a small number of particles on a diameter. For modelling the heat transport, the following assumptions are made; 1 - the system is at steady state and no reaction is carried out, 2- the system is considered to be pseudo-homogeneous, 3- there is no axial dispersion of heat, 4- there is no free convection of heat, 5- there is no radiation, 6 - the superficial velocity is constant over the radius, 7 - the pressure is constant in the packed bed, 8- the wall temperature is constant, 9- the physical properties of the gas and the solid are independent of the temperature and 10- the inlet temperature profile can be described by a parabola.

A heat balance for an infinitesimally small disc, assuming constant radial temperature, yields the following dimensionless, pseudo-homogeneous one-dimensional model:

$$
\frac{\partial \theta^{M C}}{\partial \omega}=-4 S P^{\ominus} \theta^{M C}, \quad \text { with the inlet condition: } \quad \omega=0, \quad \theta^{M C}=\theta_{0}^{M C}
$$

Solving eq. (1) together with eq. (2) yields:

$$
\theta^{M C}=\theta_{0}^{M C} \exp \left\{-4 S^{P} \omega\right\}
$$

Equation (3) describes the axial temperature profile with only one model parameter $S \boldsymbol{f}^{\boldsymbol{P}}$, containing the overall heat transfer coefficient $U_{\text {ov. }}$

A heat balance for an infinitesimally small ring yields the following dimensionless, pseudo-ho- 
mogeneous two-dimensional model:

$$
\frac{\partial \theta}{\partial \omega}=\frac{1}{B 0_{h, r}^{\ominus}} \frac{1}{\rho} \frac{\partial}{\partial \rho}\left[\rho \frac{\partial \theta}{\partial \rho}\right]
$$

Subject to:

$$
\begin{array}{lll}
\omega=0, & \text { all } \rho, & \theta=1-A \rho^{2} \\
\rho=0, \text { all } \omega, & \frac{\partial \theta}{\partial \rho}=0 \\
\rho=1, \text { all } \omega, & \frac{\partial \theta}{\partial \rho}=-\theta i_{t} \theta
\end{array}
$$

Equation (4) together with eqs. (5a)-(5c) can be solved to yield:

$$
\theta(\rho, \omega)=2 \sum_{i=1}^{-}\left\{\frac{\left.\left(B i_{t} \beta_{i}^{2}+4 A B i_{t}-2 A \beta_{i}^{2}-A B i_{t} \beta_{i}^{2}\right) J_{0}\left(\beta_{i} \rho\right)\right]}{\beta_{i}^{3}\left[\beta_{i} J_{0}\left(\beta_{i}\right)+B i_{p} J_{1}\left(\beta_{i}\right)\right]} \exp \left[\frac{-\beta_{i}^{2} \omega}{B 0_{h, r}^{\Theta}}\right]\right\}
$$

In which $\beta_{i}$ is found from:

$$
\beta_{i} \nu_{i}\left(\beta_{j}\right)-B i_{i} J_{0}\left(\beta_{j}\right)=0
$$

Equation (6) describes the axial and radial temperature profiles with two model parameters Bo, and $B i$, containing the effective radial heat conductivity $\lambda_{\partial, r}$ and the wall heat transfer coefficient hw, respectively.

Values for $\theta 0^{\mathcal{M} C}, U_{o v}, A, \lambda_{\theta, r}$ and $h_{w}$ for the two models are obtained by fitting eqs (2), (3), (5a) and $(6)$ to experimentally determined temperature profiles.

\section{EXPERIMENTAL SET-UP}

The set-up to measure radial and axial temperature profiles contains three stainless steel wallcooled tubes, with a length of $1.33 \mathrm{~m}$ and inner diameters of $49.9,63.5$ and $99.0 \mathrm{~mm}$, respectively. The tubes are filled with a packing and cooled at the wall with water of about $283 \mathrm{~K}$, flowing through a jacket. Hot air with a temperature of about $333 \mathrm{~K}$. flows upwards through the tubes and is cooled down at the wall. In the steady state, the radial temperature profile is measured in the packed bed near the top with 7 to $15 \mathrm{~K}$-type thermocouples of $0.5 \mathrm{~mm}$ diameter, fixed in a non-conducting rectangular rod of $2 \times 2 \mathrm{~mm}$, which is placed radially through the centre of the packed bed. The temperature of the gas at the inlet of the packed bed. the coolant temperature at the intet and outlet. the pressure before and after the bed and the gas flow rate are also measured. During the measurements, the bed can easily be repacked by fluidizing the packing. In Fig. 1 an example of a set of measured radial temperature profiles is given, after repacking the bed only. Radial temperature profiles at different axial positions are obtained by lowering the bed support in the tubes

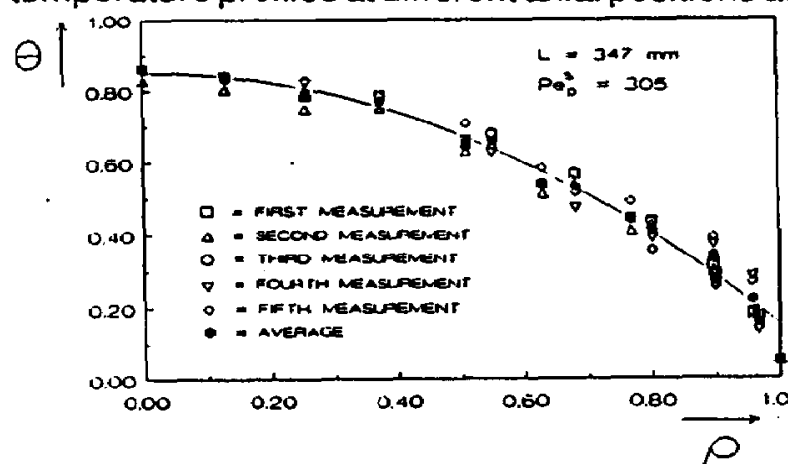

Figure 1; Experimentally determined radial temperatures and fitted parabolic profile for glass spheres with $\delta_{p}=7.2 \mathrm{~mm}$. Results for a tube with $D_{l}=99.0 \mathrm{~mm}$ and for a certain bed length and gas llow rate. and adding extra packing material at the top. Combination of the averaged radial temperature profiles, as obtained for different axial positions at the same experimental conditions, yields a temperature field for the whole tube. All experiments reported here have been pertormed with air at atmospheric pressure. For a more detailed description of the set-up and the measuring procedure, see Borkink (1991).

\section{CORRELATIONS FOR THE EFFECTIVE TRANSPORT COEFFICIENTS}

Experimental values for $\lambda_{\theta, r}, h_{W}$ and $U_{o v}$ are obtained for different gas flow rates, tube diameters and packings. In Figs 2 and 3 experimental values 


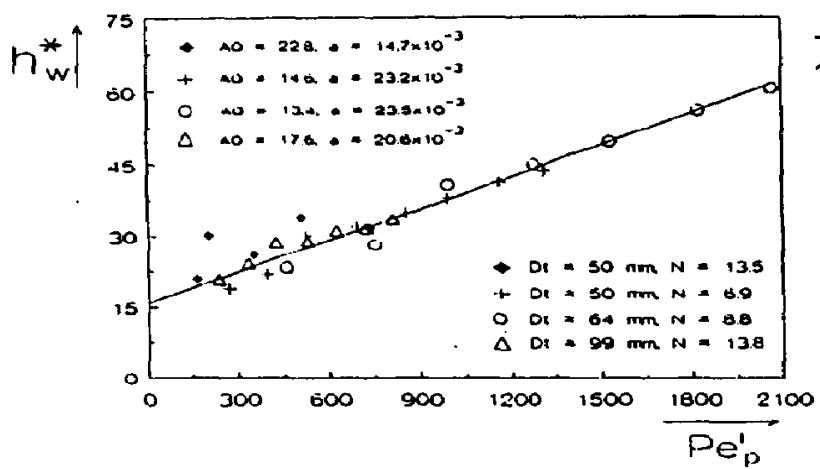

Figure 2; Best tit values for $\lambda_{e . r}$ as a function of the gas ilow rate for glass spheres with $\sigma_{p}^{\circ}=3.7$ or $7.2 \mathrm{~mm}$.

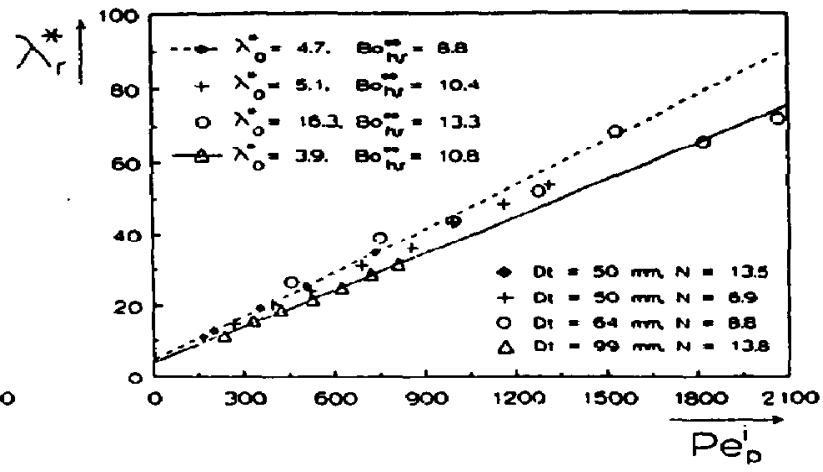

Figure 3; Best fit values for $h_{w}$ as a function of the gas flow rate for glass spheres with $\phi_{p}=3.7$ or $7.2 \mathrm{~mm}$.

for the first two parameters are given, for a packing consisting of glass spheres. Other packings investigated consisted of alumina cylinders and Raschig rings. From these figures it can be seen that the tube diameter does not seem to have any influence on the values for $\lambda_{e, r}$ and $h_{w}$. The effective radial heat conductivity, as obtained from the experimental set-up, could bestbe correlated as a function of the gas flow rate by;

$$
\lambda_{r}^{*}=\lambda_{o}^{*}+\frac{P e_{\rho}^{s}}{B 0_{h, r}^{\infty}}
$$

in which:

$$
\begin{aligned}
& \lambda_{0}^{*}=4.7 \text { and } B o_{h . r}^{\infty}=8.8 \text { for glass spheres with } \sigma_{\rho}^{\infty}=3.7 \mathrm{~mm} \\
& \lambda_{0}^{*}=6.2 \text { and } 80_{h . r}^{\circ}=10.9 \text { for glass spheres with } \sigma_{p}^{\circ}=7.2 \mathrm{~mm} \\
& \lambda_{0}^{-}=4.0 \text { and } B O_{h_{i},}^{-}=7.6 \text { for alumina cylinders with } \sigma_{p}^{2}=5.9 \mathrm{~mm} \\
& \lambda_{j}^{*}=4.5 \text { and } B O_{h, r}^{\circ}=4.2 \text { for alumina Raschig rings with } \sigma_{p}^{2}=6.2 \mathrm{~mm}
\end{aligned}
$$

The wall heat transfer could best be correlated by:

$$
h_{w}^{*}=A O+a P e_{\rho}^{j}
$$

in which:

$$
\begin{array}{ll}
A O=16.3 \text { and } a=0.022 & \text { for glass spheres } \\
A O=10.1 \text { and } a=0.021 & \text { for alumina cylinders } \\
A D=17.9 \text { and } a=0.018 & \text { for alumina Raschig rings }
\end{array}
$$

The overall heat transfer coefficient could best be correlated by:

$$
\frac{1}{v_{\text {ov }}}=\frac{1}{h_{w}^{*}}+\frac{N}{\beta \lambda_{\text {o.r }}^{*}}
$$

together with the correlations for $\lambda_{e, r}^{*}$ and $h_{w}^{m}$ as given above. The best fit value for the so called "lump factor" $\beta$ was 7.4, for all the available data. For a more general discussion of these and other results see Borkink and Westerterp (1992a).

\section{CONFIDENCE INTERVALS}

It is important to know the confidence intervals for the effective heat transport coefficients, as obtained from cold-flow experiments. Also it is important to know if, and to what extent, the parameters as used in a model description are cross-correlated. It is possible to show how the fit parameters $\lambda_{\theta, r}$ and $h_{w}$ are cross-correlated by looking at the shape of the target function for different values of the parameters. A contour of the target function in a $\lambda_{e, r}-h_{w}$ plain, containing $68 \%$ of the probability distribution for the best fit values, is given in Fig. 4. In this figure also the value is given for the parameter $\%$, which is used in the following equation: 


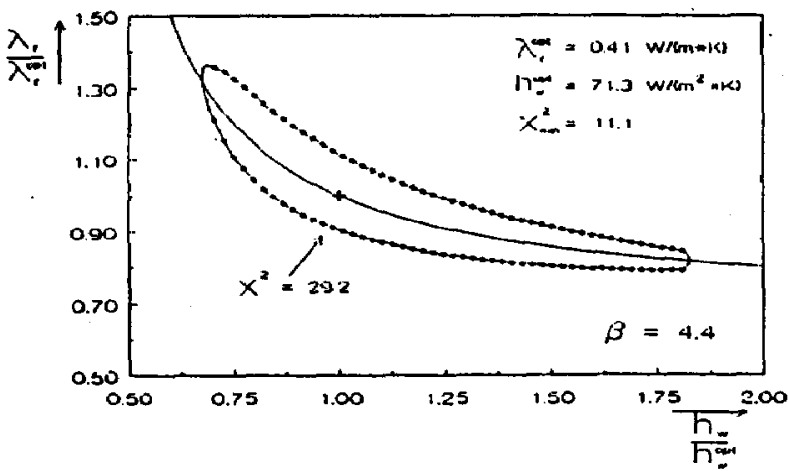

Figure 4; Confidence region for a tube with $D_{t}=49.9 \mathrm{~mm}$, fillod with glass spheres of $\infty \mathrm{p}=7.2 \mathrm{~mm}$ and for $P e_{p}^{s}=105$.

$$
\frac{\lambda_{e, r}}{\lambda_{\text {opr }}^{o p t}}=\frac{1}{\left[1+\frac{\gamma \lambda_{e . r}^{o p t}}{D_{t} h_{w}^{o p t}}\left\{1-\left(\frac{h_{w}^{o p t}}{h_{w}}\right)\right\}\right]}
$$

to describe the line through the minimum in the target function $\chi^{2}$. Equation (11) is derived from the lump equation, as given by Eq. (10), assuming $U_{\text {ov }}$ is constant. The factor $\gamma_{\text {, }}$ as used in eq. (11), should not be confused with the lump factor as given in literature, see e.g. Crider and Foss (1965). Eq. (11) is only used to show that the cross-correlation of $\lambda_{\theta, r}$ and $h_{w}$ can be described by an equation that is very close - but not equal - to the lump equation.

\section{CHOICE OF THE INLET BOUNDARY CONDITION.}

In literature often a length dependence of the heat transport coefficients is observed. In the previous section we assumed the radial gas inlet temperature to be parabolically shaped, see eq. (5a). However, often the following inlet condition is used:

$$
\omega=0 \text {, all } \rho . \quad \theta=1
$$

In Fig. 5 best fit values for the overall heat transfer coefficient Uov are given for different values of

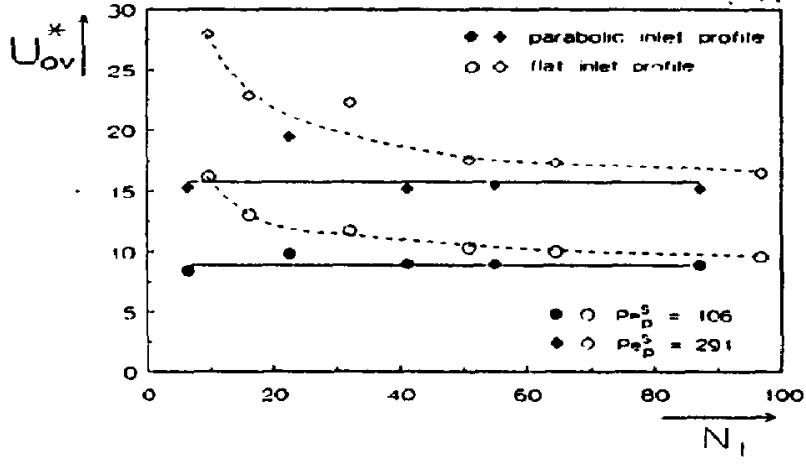

Figure 5; Uverall heat transfer coefficients for different bed lengths, for a iube with $D_{l}=99.0 \mathrm{~mm}$ and filled with alumina Raschig rings of $\delta_{0}^{\circ}=6.2 \mathrm{~mm}$.

werts infet boundary condition:

$$
\omega=0, \quad \frac{\partial \theta^{M C}}{\partial \omega}=-P e_{\mathrm{h} . \mathrm{a}}^{\Theta}\left(1-\theta^{M C}\right)
$$
the number of particles on the bed height $N$. These figures are calculated for the case a parabolic inlet temperature profile is used, as well as for a radially flat inlet temperature profile, based on the centre temperature at the inlet. From these figures it can be seen that a "length effect" is nearly absent in case a parabolic inlet temperature profile is used. For a more general discussion of the influence of the choice of the inlet boundary condition see Borkink et al. (1992b).

Assuming a radially flat inlet temperature profile, whereas the actual profile is curved, may also lead to an apparent influence of an axial dispersion of heat. An overestimation of the inlet gas temperature - in case of cooling - can be compensated for by a assuming a lower temperature or a "temperature jump" at the inlet, as is done with the Danck-

Because eq. (13) can compensate for the over-or underestimation of the inlet gas temperature, also the apparent length dependence of the transport coefficients seemingly vanishes if axial dispersion of heat is included in the model equations. see Borkink and Westerterp (1992c).

\section{INFLUENCE OF A RADIAL VELOCITY PROFILE.}

The influence of a non-constant radial porosity and velocity profile was studied theoretically, as well as experimentally, using a first order approximation for these profiles, see Borkink (1991). in this approximation the packed bed is divided into two regions, each with a different but constant 


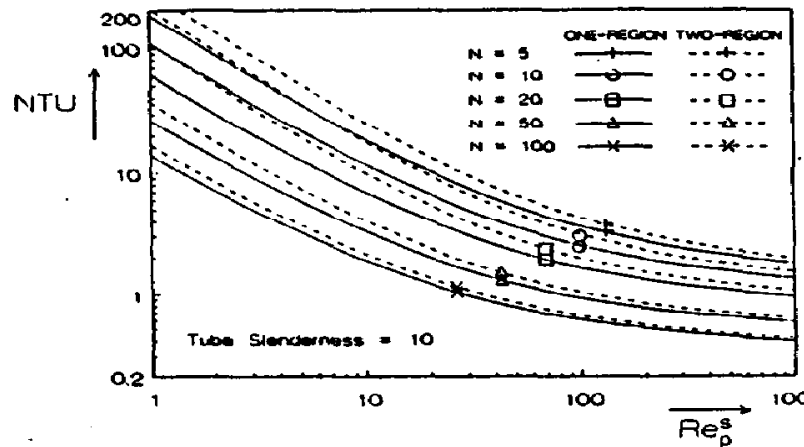

Figure 6; Calculated values for NTU for laboratory conditions with $\Gamma=10$ and $\lambda_{\bullet, r} \neq k(\Omega)$. constant over the radius. As can be seen from Fig. 6 , the NTU is always higher in case a a two-region model is used, due to the higher volumetric flow rate near the wall. Also, it can be shown that if best - fit values for the heat transport coefficients are obtained from cold-flow experiments. the two-region model yields a lower $\lambda_{a}, r$. compared to the value obtained from the one-region model.

\section{CONCLUSIONS}

One should be very careful in choosing the inlet boundary condition, when modelling the heat transport in wall-cooled packed beds. If the inlet temperature profile is assumed to be radially flat, whereas the actual profile is curved, an apparent length dependence of the heat transport coefficients and an apparent influence of an axial dispersion can be found. The presence of a radial superficial velocity profile may lead to a higher overall rate of radial heat transport. The effective radial heat conductivity and the wall heat transfer coefficient are found to be strongly cross-correlated and both parameters are found to be independent of the tube diameter.

\section{NOTATION}

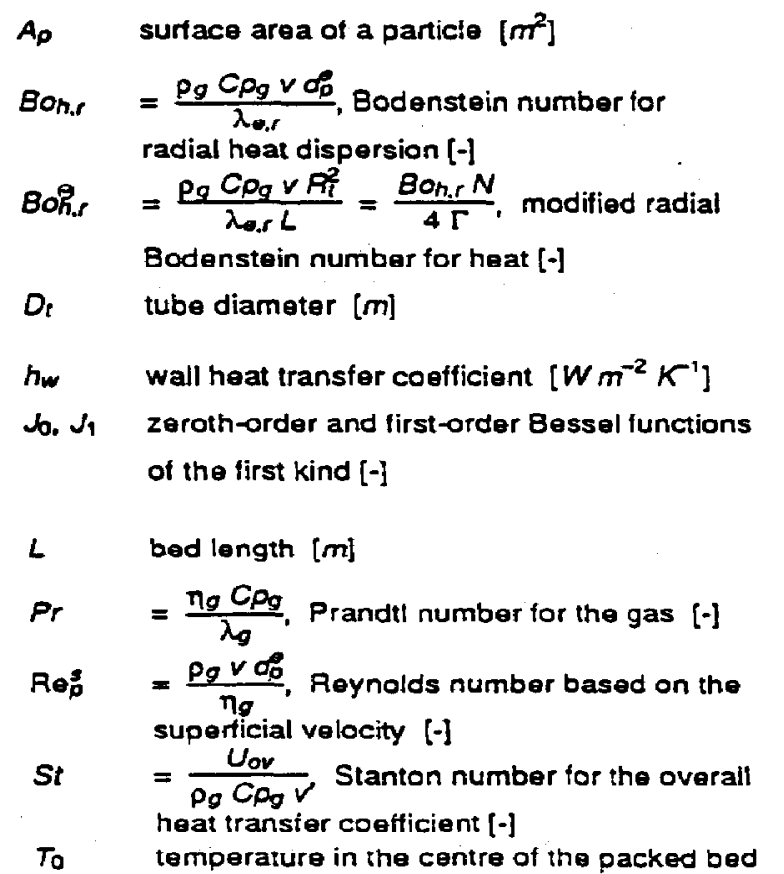
Bir $=\frac{h_{w} R_{l}}{\lambda_{e, r}}$, tube Biat number $[-]$
Bö.r Bodenstein number for heat at fully developed turbulent flow [-]
$C_{p g}$ specific heat of the gas at constant pressure
[ $J \mathrm{~kg}^{-1} K^{-1}$ ]
$d_{p}=\frac{6 V_{p}}{A_{p}}$. equivalent diameter of a sphere $[\mathrm{m}]$
$h_{w}^{*}=\frac{h_{w} d_{p}^{e}}{\lambda_{g}}$. dimensionless wall heat transfer coefficient [-]
$N=\frac{D_{1}}{d_{p}^{*}}$, number of particles on a diameter $[-]$
$P_{\theta p}^{s} \quad=\frac{P_{q} C \rho_{g} \vee d_{0}}{\lambda_{g}}=$ Rep Pr, molecular Peclet number based on the superficial velocity $[-]$
Fi tube radius [m]
$r$ radial coordinate [m]
$S^{\rho}=\frac{U_{o v} L}{\rho_{g} C_{\rho_{g}} \vee D_{l}}=$ St $\Gamma$. modified Stanton number $[-]$
$T$ temperature [K]
Uov overall heat iranster coefficient $\left[\mathrm{W} \mathrm{m}^{-1} K^{-1}\right.$

porosity and superficial velocity, called the two-region model. The gas flow rate through the wall the total gas flow through the two zones is equal to the average. By doing so the heat balance for a wall-cooled packed bed, in which a hot gas is lytically. The radial superficial velocity profiles on which the calculations were based, were taken from literature [Vortmeyer and Schuster (1983)]. In Fig. 6 the calculated number of heat transfer units NTU
is given as a function of the Reynolds number, for diameter. Literature relations were used for the heat transfer coefficients and $\lambda_{\theta}, r$ was assumed different values of the number of particles on a 
at the first axial positions [K]

$V_{p} \quad$ volume of a particle $\left[\mathrm{m}^{3}\right]$

$v$ superficial gas velocity $\left[m \mathrm{~s}^{-1}\right]$

$x^{2}$

$=\sum_{i=1}^{n}\left(\frac{\theta_{i}-\theta\left(\rho_{,}, \omega, U_{o v} \lambda_{2,}, h_{w}\right)}{\sigma i}\right)^{2}$

target function [-]

$\Gamma \quad=\frac{L}{D_{i}}$, tube slendemess $[-]$

$\lambda_{\text {o, }}$ effective radial heat conductivity $\left[W \mathrm{~m}^{-1} K^{-1}\right]$

$\lambda_{r}^{*} \quad=\frac{\lambda_{\theta}}{\lambda_{g}}$, dimensionless effective radial heat conductivity [-]

P $\quad=\frac{r}{R_{l}}$, dimensioniess radial coordinate [-]

$\sigma \quad$ standard doviation [-]

$\theta^{\mu C}=2 \int_{0}^{1} p \theta(p, \omega) \phi$, mean-cup temperature [-]
$U_{o v}=\frac{U_{o v} d_{\rho}^{\rho}}{\lambda_{g}}$, dimensionless overall heat transfer coefficient [-] axial coordinate $[m]$

average porosity of the bed [-]

dynamic viscosity of the gas [Pa s] heat conductivity of the gas $\left[W \mathrm{~m}^{-1} \mathrm{~K}^{-1}\right]$

effective heat conductivity of the packed bed with a stagnant fluid $\left[W \mathrm{~m}^{-1} \mathrm{~K}^{-1}\right]$ $=\frac{z}{L}$, dimensionless axial coordinate $[-]$ density of the gas $\left[\mathrm{kg} \mathrm{m}^{-3}\right]$ $=\frac{\left(T-T_{C l}\right)}{\left(T_{0}-T_{C l}\right)}$, dimensionless temperature $[-]$

\section{Subscripts}

Superscripts

$\begin{array}{ll}\text { ci } & \begin{array}{l}\text { coolant } \\ \text { effective }\end{array} \\ \mathbf{g} & \text { gas } \\ \mathbf{p} & \text { particle } \\ \mathbf{r} & \text { radial } \\ \mathbf{t} & \text { tube } \\ \mathbf{w} & \text { wall }\end{array}$

- equivalent

i interstitial

s superticial

\section{REFERENCES}

Borkink, J.G.H., 1991, Heat transport in wall-cooled packed beds of low tube-to-particle diameter ratio, thesis Twente University of Technology, Enschede, The Netherlands.

Borkink, J.G.H. and Westerterp, K.R., 1992a, Influence of tube and particle diameter on heat transport in packed beds., submitted to A.J.Ch.E. $J$.

Borkink, J.G.H., Borman, P.C. and Westerterp, K.R., 1992b, Modelling of radial heat transpont in wall-cooled packed beds - Confidence intervals of estimated parameters and choice of boundary conditions., excepted for publication by Chom. Eng. Comm.

Borkink, J.G.H. and Westerterp, K.R., 1992c, The signilicance of axial heat dispersion for the description of heat transpon in wall-cooled packed beds., excepted for publication by Chem. Eng. Techn.

Crider, J.E. and Foss, A.S., 1965, Effective wall heat transfer coefficients and thermal resistances in mathematical models of packed beds. A.I.Ch.E. J. 11, 1012-1019.

Vortmeyer, D. and Schuster, J., 1983, Evaluation of steady flow profiles in rectangular and circular packed beds by a variational method. Chem. Engng. Sci. 38, 1691-1699. 